\title{
The state of the art of the minimally invasive thoracic surgery in Italy
}

Our discipline is in the centre of revolutionary changes. Video-assisted thoracic surgery (VATS) is nowadays considered an acceptable approach for the treatment of early-stage non-small cell lung cancer, as recommended by current guidelines. VATS approaches present a decreased operative trauma with a subsequent reduction in both postoperative and long-term pain when compared to thoracotomy, without differences in oncological and survival outcomes.

The technological innovation and the unlimited possibilities of analysing big data are causing radical changes in all areas of health, and thoracic surgery is at the forefront of these upheavals. The continuous capture of clinical parameters, the capture of biomedical interfaces, data from the biomolecular analysis of cancers, or the progress of imaging medical have changed our professional practices. At the same time, artificial intelligence invests our operating theatres. Surgery comes mini-invasive, robot-assisted, and adopts an augmented reality through vision 3D and fusion imaging. This context modifies the architecture of our techniques that have become hybrid and increasingly multidisciplinary.

The focused issue "Minimally Invasive Thoracic Surgery in Italy: State of the Art" aims to review the Italian experience in minimally invasive thoracic surgery and addresses the potential benefits and limitations of the VATS and RATS in the thoracic surgical procedures.

We have some strength to deal with these challenges. This strategy was achieved by the unprecedented success of our VATS group database. The ability to follow quantitatively and qualitatively our activities, both at the team and at the national level, have not the unique purpose of evaluating surgical practices. It also helps to anticipate future needs in our discipline. The success of this ambitious project is based on active participation of our community in the VATS group project. Our young colleagues are already on board, and their enthusiasm is communicative: they are our future.

\section{Acknowledgements}

None.

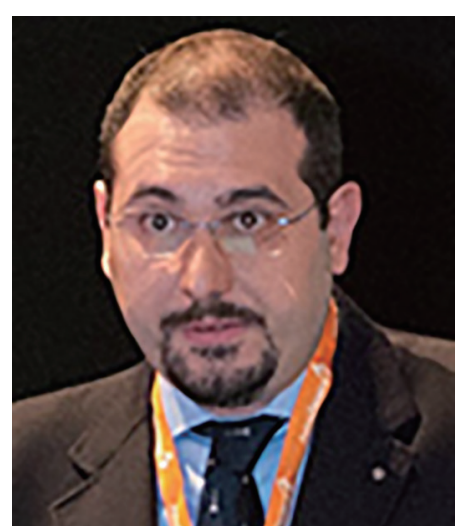

Luca Bertolaccini

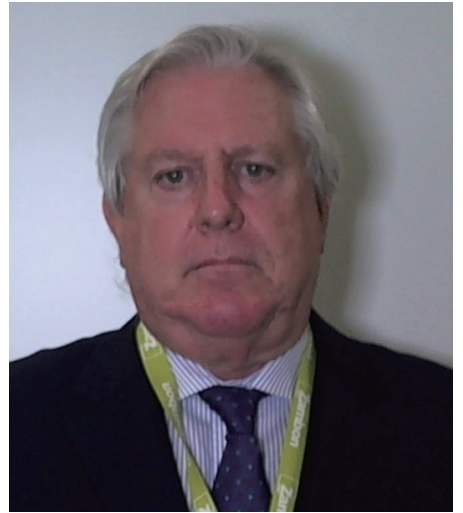

Roberto Crisci 


\section{Luca Bertolaccini, MD, PhD, FCCP}

Department of Thoracic Surgery, Maggiore Teaching Hospital, Bologna, Italy.

(Email: luca.bertolaccini@gmail.com)

Roberto Crisci, $\mathrm{MD}, \mathbf{P h D}$

Department of Thoracic Surgery, University of L'Aquila, G. Mazzini Hospital, Teramo, Italy. doi: $10.21037 /$ jovs.2018.05.05

Conflicts of Interest: The authors have no conflicts of interest to declare.

View this article at: http://dx.doi.org/10.21037/jovs.2018.05.05

doi: 10.21037/jovs.2018.05.05

Cite this article as: Bertolaccini L, Crisci R. The state of the art of the minimally invasive thoracic surgery in Italy. J Vis Surg 2018;4:89. 